\title{
Journal of Environmental Analytical Chemistry
}

\section{Analysis of 19 preservatives in Polyvinyl Alcohol Cooling Towels Used in Japan by High Performance Liquid Chromatography with Photo Diode Array Detector}

Tsuyoshi Kawakami ${ }^{\star}$, Kazuo Isama and Yoshiaki Ikarashi

Division of Environmental Chemistry, National Institute of Health Sciences, Tokyo, 158-8501, Japan

${ }^{*}$ Corresponding author: Tsuyoshi Kawakami, Division of Environmental Chemistry, National Institute of Health Sciences, Tokyo, Japan, Tel: +81-3-3700-1141/367; Email: tkawa@nihs.go.jp

Rec date: October 28, 2014, Acc date: December 14, 2014, Pub date: December 16, 2014

Copyright: (C) 2014 Tsuyoshi Kawakami, This is an open-access article distributed under the terms of the Creative Commons Attribution License, which permits unrestricted use, distribution, and reproduction in any medium, provided the original author and source are credited.

\begin{abstract}
The cases of contact dermatitis due to using polyvinyl alcohol (PVA) towel containing isothiazolinone preservatives have been reported in Japan and we had investigated the concentrations of isothiazolinones and the removal of these preservatives from PVA towels by washing before initial use in the previous study conducted from 2011 to 2012. However, the clinical information regarding contact dermatitis due to using PVA cooling towels containing other preservatives was provided from the supplier of PVA towel in the summer of 2013. Thus, we analyzed 19 preservatives in 21 PVA towels by high performance liquid chromatography with photo diode array detector in this study. A good separation of these preservatives was observed using InertSustain ${ }^{\circledR}$ Phenyl column and $0.1 \%$ formic acid solution as the mobile phase. 2-Methyl-4-isothiazolin-3-one and 5-chloro-2-methyl-4isothiazolin-3-one were detected in 16 samples, including the sample which was sold in a dry condition; the concentrations of these substances ranged from 7.9-84 $\mu \mathrm{g} / \mathrm{g}$-wet and 9.5-173 $\mu \mathrm{g} / \mathrm{g}$-wet, respectively $(2.9 \mu \mathrm{g} / \mathrm{g}$-dry and $9.3 \mu \mathrm{g} / \mathrm{g}$-dry, respectively). 2-n-Octyl-4-isothiazolin-3-one was detected in one sample (484 $\mu \mathrm{g} / \mathrm{g}$-wet). 2Bromo-2-nitropropane-1,3-diol (BP) was detected in 15 samples, including the sample which was sold in a dry condition; its concentration ranged from 68-2303 $\mu \mathrm{g} / \mathrm{g}$-wet (160 $\mu \mathrm{g} / \mathrm{g}$-dry). 2-Phenoxyethanol (PE) and benzoic acid (BA) were detected in 3 and 2 samples, and their concentrations ranged from 99-3171 $\mu \mathrm{g} / \mathrm{g}$-wet and 1896-23043 $\mu \mathrm{g} / \mathrm{g}$-wet. Other preservatives were not detected. Although isothiazolinone preservatives were detected in 17 samples, the product notes of 10 products, including the product with clinical information, did not describe about the use of isothiazolinone preservatives. Since PVA cooling towels in contact with human skin for a long time, the PVA cooling towels should be used with caution, especially on patients who are already sensitive to isothiazolinone preservatives. Furthermore, we evaluated the effectiveness of the washing process on the removal of BP, PE, and BA from the PVA towels before their initial use. The results of this laboratory-simulated washing procedure suggest that contact dermatitis is likely not related to the presence of BP, PE, and BA in washed PVA towels.
\end{abstract}

Keywords: Polyvinyl alcohol towel; Preservatives; High performance liquid chromatography; Photo diode array detector; Phenyl column; Household products; Contact dermatitis

\section{Abbreviations: \\ PVA: polyvinyl alcohol; MI: 2-methyl-4-isothiazolin-3-one; CMI: 5- chloro-2-methyl-4-isothiazolin-3-one; OIT: 2-n-octyl-4- isothiazolin-3-one; BP: 2-bromo-2-nitropropane-1,3-diol; PE: 2- phenoxyethanol; BA: benzoic acid; HPLC: high performance liquid chromatography; PDA: photo diode array detector}

\section{Introduction}

Recently, several household products have been developed to cool the body, including gel-based products based on high water content superabsorbent polymers that can dissipate heat from the surface of the skin and polyvinyl alcohol (PVA) towels that provide a cooling sensation by absorbing heat on the skin resulting from hyper-efficient water evaporation. In general, PVA towels are moistened with water to prevent them from breaking before their departure from the factory, and water contained preservatives are used in PVA towels to protect against mildew (Figure 1). These products are especially popular during the humid summer season in Japan. However, several cases of contact dermatitis due to the use of these cooling products were reported in Japan [1,2]. Isothiazolinone preservatives were implicated in the cases of contact dermatitis. Therefore, we investigated several preservatives in the gel-products [3] and PVA cooling towels [4] in Japanese markets in 2010 (gel-products) and from 2011 to 2012 (PVA cooling towels). These studies were confirmed the use of isothiazolinone preservatives including 2-methyl-4-isothiazlin-3-one (MI), 5-chloro-2-methyl-4-isothiazolin-3-one (CMI), and 2-n-octyl-4isothiazolin-3-one (OIT) and their concentrations in the gel-products and PVA cooling towels by liquid chromatography/tandem massspectrometry. Furthermore, we examined the effectiveness of washing on the removal of preservatives from new PVA towels prior to their initial use, because some manufactures recommended that customers wash new towels before using them to remove preservatives [4]. The presence of residual MI, CMI, and OIT in the washed towels was confirmed.

In the summer of 2013, the clinical information regarding contact dermatitis cases related to PVA cooling towels using other types of preservatives was provided from the supplier. However, only isothiazolinone preservatives were studied and the presence of other preservatives was not investigated in the previous study. Therefore, the aim of this study was to clarify the presence of various preservatives in PVA towels and quantify their concentrations using high performance liquid chromatography with photo diode array detector (HPLC/PDA). Furthermore, we also evaluated the effectiveness of the washing 
process in the removal of several preservatives from PVA towels prior to their initial use.

(a)

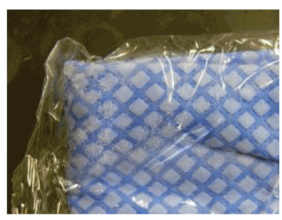

(b)

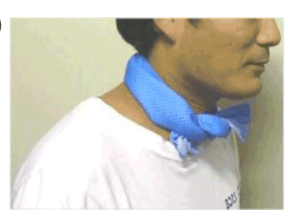

Figure 1: (a) Unopened PVA cooling towel. Water drops can be seen inside the package. (b) An example of usage of PVA cooling towel.

\section{Materials and Method}

\section{Samples}

Although the PVA towel product which caused contact dermatitis could not obtained, a same PVA towel with the different package was obtained from the supplier (Sample No. 1). Other twenty PVA towels were purchased from online shops and retail stores in Saitama prefecture and Tokyo, Japan from September to December, 2013. All PVA towels were for body cooling, except for No. 21 (used for car washing). All of the products were moist at the time of purchase, with the exception of No. 9.

\section{Materials and reagents}

A mixture of MI (3.63\%) and CMI (10.85\%) was obtained from Waterstone Technology (Carmel, IN, USA). 2-n-Octyl-4isothiazolinone-3-one (OIT), 1,2-benzoisothiazolin-3-one (BIT), benzoic acid (BA), phenoxyethanol (PE), bronopol (BP), 5-bromo-5nitro-1,3-dioxane (Bronidox), 2-mercaptobenzothiazole (MBT), 3ido-2-propynyl N-butylcarbamate (IPBC), and parabens [PBs; methylparaben (Me-PB), ethylparaben (Et-PB), propylparaben (Pro$\mathrm{PB}$, isopropylparaben (Iso-Pro-PB), butylparaben (Bu-PB), isobutylparaben (Iso-Bu-PB), benzylparaben (Be-PB)] were purchased from Tokyo Chemical Industry (Tokyo, Japan). 4,5-Dichloro-2-noctyl-4-isothiazolin-3-one (2Cl-OIT) was obtained from AK Scientific, Inc. (Union City, IN, USA). Methyldibromo glutaronitrile (MDBGN) was obtained from Sigma-Aldrich (St. Louis, MO, USA). The chemical properties of these preservatives are listed in Table 1.

HPLC grade acetonitrile and methanol were obtained from SigmaAldrich (St. Louis, MO, USA). LC/MS grade formic acid was obtained from Wako Pure Chemical Industries, Ltd. (Osaka, Japan). Ultrapure water was produced by a Milli-Q Advantage A10 water purification system (Merck Millipore, Tokyo, Japan).

\section{Sample processing}

A $0.5 \mathrm{~g}$ of sample was cut into small pieces and placed in a glass tube with $5 \mathrm{~mL}$ of methanol, and the tube was subsequently shaken using a horizontal shaker for $30 \mathrm{~min}$. The sample solution was then filtered on a suction funnel with a glass filter, and the resulting residue was washed with methanol. The filtrate was combined with the wash, and the sample solution was concentrated to below $5 \mathrm{~mL}$ with a rotary evaporator; the temperature of the water bath was below $40^{\circ} \mathrm{C}$. Next, the total volume of the solution was adjusted to $5 \mathrm{~mL}$ using methanol. The sample solution was filtered using a PTFE filter (pore size: 0.20 $\mu \mathrm{m}, \mathrm{ADVANTEC}$ ) and analyzed by HPLC/PDA.

\section{Laboratory-simulated washing procedure}

Samples 1, 3, and 8 were used to examine the effect of a laboratorysimulated washing procedure on the removal of isothiazolinone preservatives from new PVA towels using a previously reported procedure [4]. Each sample was divided into $2 \mathrm{~cm}^{2}$, of which 4 pieces were placed into a glass tube. Afterwards, $20 \mathrm{~mL}$ of ultrapure water $\left(25^{\circ} \mathrm{C}\right)$ was added to the glass tube, and the tube was shaken using a horizontal shaker at $300 \mathrm{rpm}$ for $30 \mathrm{sec}$. After the shaking, the sample solution was filtered, and the total volume of the sample solution was adjusted to $25 \mathrm{~mL}$ by the addition of ultrapure water. This washing process was repeated three times, and the sample solution obtained after each wash was analyzed individually. The sample solutions were filtered through a PTFE filter and analyzed by HPLC/PDA. The experiments for every sample were carried out in quadruplicate.

\section{HPLC analysis conditions}

All samples were analyzed using a Shimadzu NexeraX2 HPLC system (Shimadzu, Kyoto, Japan) consisting of two LC-30AD pumps, a CTO-30A column oven, SPD-M30A photodiode array detector, SIL-30AC auto sampler, and CBM-20A communication bus module. System control and data calibration were carried out using the Lab Solutions software (ver. 6. 11.) (Shimadzu, Kyoto, Japan). An InertSustain Phenyl column (length $150 \mathrm{~mm}$, internal diameter 3.0 $\mathrm{mm}$, particle size $3 \mu \mathrm{m}$; GL Sciences, Inc., Tokyo, Japan) was used for the separation of the target compounds. As mobile phase, eluent A of ultrapure water containing $0.1 \%$ formic acid and eluent $\mathrm{B}$ of acetonitrile were used. The gradient elution began with $25 \%$ of eluent B, which was held constant for $2 \mathrm{~min}$, and increased linearly to $30 \%$ over $9 \mathrm{~min}$, which was held constant for another $3 \mathrm{~min}$. Then, eluent $\mathrm{B}$ increased linearly to $90 \%$ over $3 \mathrm{~min}$, which was held constant for another $5.5 \mathrm{~min}$. The flow rate, injection volume, and oven temperature were $0.6 \mathrm{~mL} / \mathrm{min}, 5 \mu \mathrm{L}$, and $40^{\circ} \mathrm{C}$, respectively. The monitored wavelength range was from 190-600 nm.

\section{Recovery, limit of detection (LOD), and limit of quantification (LOQ) in this study}

Recovery tests were performed by adding every compound to samples that did not contain the target compounds. These compounds were added as methanol solution $(100 \mu \mathrm{L})$ and the added amounts of the compounds were as follows: MI: $1.68 \mu \mathrm{g} / \mathrm{g}$-wet; Bronidox, MDBGN, and IPBC: $50 \mu \mathrm{g} / \mathrm{g}$-wet; other analytes: $5.0 \mu \mathrm{g} / \mathrm{g}$-wet. The recovery tests were conducted in quardruplicate. 
Citation: Kawakami T, Isama K, Ikarashi Y (2015) Analysis of 19 preservatives in Polyvinyl Alcohol Cooling Towels Used in Japan by High Performance Liquid Chromatography with Photo Diode Array Detector. J Environ Anal Chem 2: 122. doi:10.4172/JREAC.1000122

Page 3 of 6

\section{Results and Discussion}

Examination of HPLC/PDA conditions and recovery, limit of detection (LOD), and limit of quantification (LOQ) in this study

Initially, the reversed-phase octadecyl column (Inertsil ${ }^{\oplus}$ ODS-4, GL Sciences Inc., Tokyo.) was used for examination of chromatographic condition. However, Et-PB and MBT, and Iso-Bu-PB, IPBC and BuPB overlapped on the chromatogram, respectively. Furthermore, these preservatives were not separated by using Inertsil ${ }^{\circ}$ ODS- 4 column under any gradient condition (data not shown). On the other hand, all target compounds were separated and good peak shapes were observed by using InertSustain ${ }^{\otimes}$ Phenyl column. Although this column was also classified to reversed-phase column, the characteristics of silica gel surface of this column were different from Inertsil ${ }^{\circ}$ ODS-4. This difference of surface characteristics might effect on the separation of the preservatives. Therefore, InertSustain ${ }^{\otimes}$ Phenyl column was used for separation in this study. HPLC chromatogram is shown in Figure 2 and the retention times obtained from chromatogram are listed in Table 2. UV-Vis spectra of these preservatives were measured by PDA to examine quantifying wave length of target compounds (Figure 3). From UV-Vis spectra of these compounds, 195, 226, 256, 273, 283, and $322 \mathrm{~nm}$ were used for the quantification of the analytes (Table 2).

\begin{tabular}{|c|c|c|c|c|c|}
\hline Name & Abbreviation & CAS & Chemical formula & M.W. & logPow \\
\hline 2-Methyl-4-isothiazolin-3-one & $\mathrm{Ml}$ & $2682-20-4$ & $\mathrm{C}_{4} \mathrm{H}_{5} \mathrm{NOS}$ & 115.15 & $0.119 \pm 0.406^{a}$ \\
\hline 2-Bromo-2-nitropropane-1,3-diol(Bronopol) & $\mathrm{BP}$ & $52-51-7$ & $\mathrm{C}_{3} \mathrm{H}_{6} \mathrm{BrNO} 4$ & 199.99 & $1.150 \pm 0.631^{\mathrm{a}}$ \\
\hline 5-Choro-2-methyl-4-isothiazolin-3-one & $\mathrm{CMI}$ & $26172-55-4$ & $\mathrm{C}_{4} \mathrm{H}_{4} \mathrm{CINOS}$ & 149.6 & $0.487 \pm 0.416^{a}$ \\
\hline Benzisothiazolin-3-one & BIT & $2634-33-5$ & $\mathrm{C}_{7} \mathrm{H}_{5} \mathrm{NOS}$ & 151.19 & $1.953 \pm 0.401^{a}$ \\
\hline 2-Phenoxyethanol & PE & $122-99-6$ & $\mathrm{C}_{8} \mathrm{H}_{10} \mathrm{O} 2$ & 138.16 & $1.2^{b}$ \\
\hline Benzoic acid & BA & $65-85-0$ & $\mathrm{C}_{7} \mathrm{H}_{6} \mathrm{O} 2$ & 122.12 & $1.87^{\mathrm{b}}$ \\
\hline Methyl 4-hydroxybenzoate (Methylparaben) & Me-PB & $99-76-3$ & $\mathrm{C}_{8} \mathrm{H}_{8} \mathrm{O}_{3}$ & 152.15 & $1.96^{\mathrm{b}}$ \\
\hline 5-Bromo-5-nitro-1,3-dioxane & Bronidox & $30007-47-7$ & $\mathrm{C}_{4} \mathrm{H}_{6} \mathrm{BrNO}_{4}$ & 212 & $0.749 \pm 0.430^{\mathrm{a}}$ \\
\hline Ethyl 4-hydroxybenzoate (Ethylparaben) & Et-PB & $120-47-8$ & $\mathrm{C}_{9} \mathrm{H}_{10} \mathrm{O}_{3}$ & 166.18 & $2.47^{\mathrm{b}}$ \\
\hline 2-Mercaptobenzothiazole & MBT & $149-30-4$ & $\mathrm{C}_{7} \mathrm{H}_{5} \mathrm{NS}_{2}$ & 167.24 & $2.41^{\mathrm{b}}$ \\
\hline $\begin{array}{l}\text { 2-Bromo-2-(bromomethyl)-pentanedinitrile (Methyldibromo } \\
\text { glutaronitrile) }\end{array}$ & MDBGN & $35691-65-7$ & $\mathrm{C}_{6} \mathrm{H}_{6} \mathrm{Br}_{2} \mathrm{~N}_{2}$ & 265.93 & $1.515 \pm 0.408^{a}$ \\
\hline Isopropyl 4-hydroxybenzoate (Isopropylparaben) & Isopro-PB & $4191-73-5$ & $\mathrm{C}_{10} \mathrm{H}_{12} \mathrm{O}_{3}$ & 180.2 & $2.34^{\mathrm{b}}$ \\
\hline Propyl 4-hydroxybenzoate(Propylparaben) & Pro-PB & $94-13-3$ & $\mathrm{C}_{10} \mathrm{H}_{12} \mathrm{O}_{3}$ & 180.2 & $3.04^{\mathrm{b}}$ \\
\hline Isobutyl 4-hydroxybenzoate (Isobutylparaben) & Isobu-PB & $2 / 3 / 4247$ & $\mathrm{C}_{11} \mathrm{H}_{14} \mathrm{O}_{3}$ & 194.23 & $3.11^{\mathrm{b}}$ \\
\hline Butyl 4-hydroxybenzoate(Butylparaben) & Bu-PB & $94-26-8$ & $\mathrm{C}_{11} \mathrm{H}_{14} \mathrm{O}_{3}$ & 194.23 & $3.57^{\mathrm{b}}$ \\
\hline 3-lodo-2-propynyl N-butylcarbamate & IPBC & $55406-53-6$ & $\mathrm{C}_{8} \mathrm{H}_{12} \mathrm{INO}_{2}$ & 281.09 & $3.383 \pm 0.490^{\mathrm{a}}$ \\
\hline 2-n-octyl-4-isothiazolin-3-one & OIT & $26530-20-1$ & $\mathrm{C}_{11} \mathrm{H}_{19} \mathrm{NOS}$ & 213.3 & $3.685 \pm 0.406^{a}$ \\
\hline Benzyl 4-hydroxybenzoate (Benzylparaben) & $\mathrm{Be}-\mathrm{PB}$ & $94-18-8$ & $\mathrm{C}_{14} \mathrm{H}_{12} \mathrm{O}_{3}$ & 228.25 & $3.56^{b}$ \\
\hline 4,5-Dichloro-n-octyl-4-isothiazolin-3-one & 2Cl-OIT & $64359-81-5$ & $\mathrm{C}_{11} \mathrm{H}_{17} \mathrm{Cl}_{2} \mathrm{NOS}$ & 282.2 & $4.335 \pm 0.743^{a}$ \\
\hline
\end{tabular}

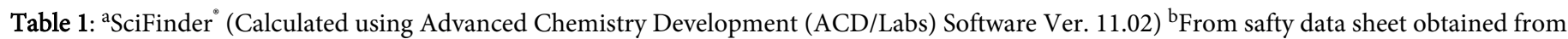
supplier; Physico-chemical properties of preservatives studied.

\section{Concentrations of target preservatives in PVA towels}

MI, CMI, OIT, BP, PE, and BA were detected in the samples, while other preservatives were not detected. Their concentrations and frequency of detection are shown in Table 3. The representative HPLC chromatogram obtained from No. 8 is shown in Figure 4. MI and CMI were detected in 16 samples including the sample (No. 9) which was sold in a dry condition; their concentrations ranged from $7.9-84 \mu \mathrm{g} / \mathrm{g}-$ wet and 9.5-173 $\mu \mathrm{g} / \mathrm{g}$-wet, respectively (in No. 9, $2.9 \mu \mathrm{g} / \mathrm{g}$-dry and 9.3 $\mu \mathrm{g} / \mathrm{g}$-dry, respectively). OIT was only detected in sample No. 10 (484 $\mu \mathrm{g} / \mathrm{g}$-wet). BP was detected in 15 samples including the dry sample
(No. 9) and its concentrations ranged from $68-2303 \mu \mathrm{g} / \mathrm{g}$-wet (in No. $9,160 \mu \mathrm{g} / \mathrm{g}$-dry). In a previous study, isothiazolinone preservatives were frequently observed [4]. In this study, BP was also frequently observed. PE and BA were detected in 3 and 2 samples and their concentrations ranged from 99-3171 $\mu \mathrm{g} / \mathrm{g}$-wet and 1896-23043 $\mu \mathrm{g} / \mathrm{g}$ wet, respectively. 
Citation: Kawakami T, Isama K, Ikarashi Y (2015) Analysis of 19 preservatives in Polyvinyl Alcohol Cooling Towels Used in Japan by High Performance Liquid Chromatography with Photo Diode Array Detector. J Environ Anal Chem 2: 122. doi:10.4172/JREAC.1000122

Page 4 of 6

\begin{tabular}{|l|l|l|l|l|l|l|}
\hline Chemicals & $\begin{array}{l}\text { Retention } \\
\text { time }\end{array}$ & $\begin{array}{l}\text { Wave } \\
\text { length }\end{array}$ & LOD $^{\mathrm{a}}$ & LOQ $^{\mathrm{b}}$ & Recoveriesa & $\mathbf{C V}$ \\
\hline (min) & $(\mathbf{n m})$ & $\begin{array}{l}\boldsymbol{(} \mathbf{\mu g} / \mathbf{g}- \\
\mathbf{w e t})\end{array}$ & $\begin{array}{l}(\boldsymbol{\mu} \mathbf{g} / \mathrm{g}- \\
\mathbf{w e t})\end{array}$ & $(\%)$ & $(\%)$ \\
\hline MI & 1.73 & 273 & 0.5 & 1.1 & 109 & 5.8 \\
\hline BP & 2.18 & 195 & 2.5 & 5.3 & 100 & 11 \\
\hline CMI & 2.68 & 273 & 0.68 & 1.4 & 104 & 2.8 \\
\hline BIT & 3.27 & 226 & 0.66 & 1.4 & 98 & 2.9 \\
\hline PE & 4.25 & 195 & 0.84 & 1.8 & 91 & 3.9 \\
\hline BA & 4.56 & 195 & 0.63 & 1.3 & 94 & 2.8 \\
\hline Me-PB & 4.95 & 256 & 0.42 & 0.9 & 98 & 1.8 \\
\hline Bronidox & 6.47 & 195 & 3.3 & 7.1 & 86 & 1.6 \\
\hline Et-PB & 7.42 & 256 & 0.52 & 1.1 & 94 & 2.4 \\
\hline MBT & 8.38 & 322 & 0.78 & 1.7 & 94 & 3.5 \\
\hline MDBGN & 8.83 & 195 & 14 & 29 & 96 & 7 \\
\hline Isopro-PB & 10.49 & 256 & 0.6 & 1.3 & 96 & 2.6 \\
\hline Pro-PB & 11.14 & 256 & 0.67 & 1.4 & 98 & 2.9 \\
\hline Isobu-PB & 15.36 & 256 & 0.29 & 0.61 & 100 & 1.2 \\
\hline Bu-PB & 16.08 & 256 & 0.3 & 0.63 & 100 & 1.3 \\
\hline IPBC & 16.73 & 195 & 8.9 & 19 & 85 & 4.5 \\
\hline OIT & 16.91 & 273 & 0.69 & 1.5 & 97 & 3 \\
\hline Be-PB & 17.06 & 256 & 0.65 & 1.4 & 102 & 2.7 \\
\hline 2CI-OIT & 18.25 & 283 & 0.61 & 1.3 & 118 & 2.2 \\
\hline
\end{tabular}

CMI is used as a water-treatment agent in various industrial processes [7], and the mixture might be also used for PVA cooling towels.

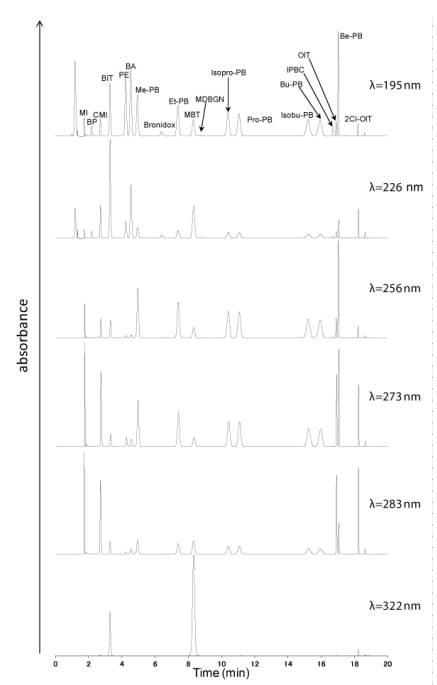

Figure 2: HPLC chromatogram of standard solution (MI: $26.9 \mu \mathrm{g} / \mathrm{mL}$; other analytes: $80 \mu \mathrm{g} / \mathrm{mL}$ ) at $195,226,256,273,283$, and $323 \mathrm{~nm}$.

\section{Effect of washing by laboratory-simulated washing procedure on removal of preservatives}

Most manufactures recommend a washing procedure to be conducted by consumers before the initial use of new PVA cooling towels. Thus, a laboratory-simulated washing procedure was performed and the removal efficiencies of MI, CMI, and OIT were examined previously [4]. In the previous study, the amount of residual isothiazolinone preservatives in washed PVA towels was reported and greater residual amounts of OIT as compared to MI and CMI were

Table 2: ${ }^{\text {a }}$ LOD was calculated according to JIS, K0124:2011using the standard deviation $(\rho)$ and $\mathrm{t}$-value $(\mathrm{t}=4.71, \mathrm{n}=4)$ obtained from the recovery test (MI: $1.675 \mu \mathrm{g} / \mathrm{g}$-wet, Bronidox, MDBGN and IPBC: 50 $\mu \mathrm{g} / \mathrm{g}$-wet, others: $5 \mu \mathrm{g} / \mathrm{g}$-wet); ${ }^{\mathrm{b}} \mathrm{LOQ}$ was calculated as ten times of $\rho$; Retention time, quantifying wave length, limit of detection (LOD), limit of quantification (LOQ), and recoveries of preservatives studied.

The product notes about the use of isothiazolinone preservatives did not describe on ten kinds of PVA towel samples that contained isothiazolinone preservatives. Furthermore, among these samples, only one sample indicated the use of preservatives and six samples denoted only the use of BA or citric acid. In the other 3 samples, the product note was not present or could not be read. In the case of No. 13, although the product description claimed "isothiazolinone preservatives were not used in this product", MI and CMI (10 and 24 $\mu \mathrm{g} / \mathrm{g}$-wet, respectively) were detected.

The use of PE and BA were described on the case of products; however, the use of BP was not denoted in all samples that contained BP. Although product notes about the use of PE and BA were present on No. 1 and 4, these preservatives were not detected, while MI, CMI, and BP were detected. Thus, the causative substances of contact dermatitis due to using No. 1 might be MI and CMI. BP was detected in 12 samples with MI and CMI. Since the mixture of BP, MI, and noted and attributed to the differences in their affinities to PVA-based materials because of their hydrophobicities [4].

In this study, we examined the removal efficiencies of BP, BA, and PE from samples 1,3 , and 8 , respectively. The results are shown in Figure 5. After the first washing procedure, $97 \%, 84 \%$, and $63 \%$ of BP, $\mathrm{PE}$, and BA were removed from the towels, and after all of the washing procedures, only $0.23 \%$ and $0.45 \%$ of $\mathrm{BP}$ and PE remained in the PVA towels. In contrast, $5.4 \%$ of BA remained in the PVA towels after all the washing procedures. While the hydrophobicities of isothiazolinone preservatives affected their retention in PVA towels after washing in the previous study [4], the octanol-water partition coefficients (logPow) of BP, PE, and BA are similar (Table 1), and therefore might not be correlated to the retention. More BA than BP and PE was retained in the towel after washing, potentially because of the large amount of in the PVA towel (BA: $23043 \mu \mathrm{g} / \mathrm{g}$-wet). 
Citation: Kawakami T, Isama K, Ikarashi Y (2015) Analysis of 19 preservatives in Polyvinyl Alcohol Cooling Towels Used in Japan by High Performance Liquid Chromatography with Photo Diode Array Detector. J Environ Anal Chem 2: 122. doi:10.4172/JREAC.1000122

Page 5 of 6

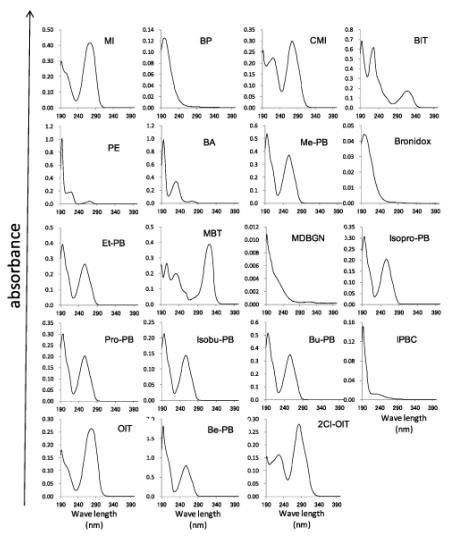

Figure 3: UV-Vis spectra of each preservative peaks obtained from standard solution.

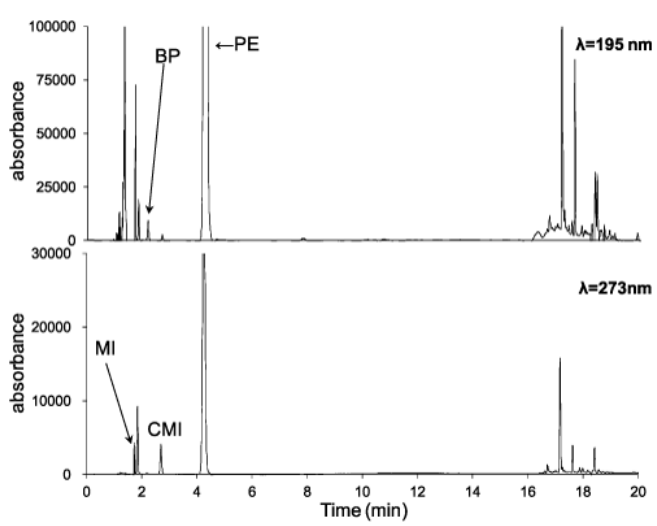

Figure 4: HPLC chromatogram of sample solution diluted to $1 / 10$ (No. 8).

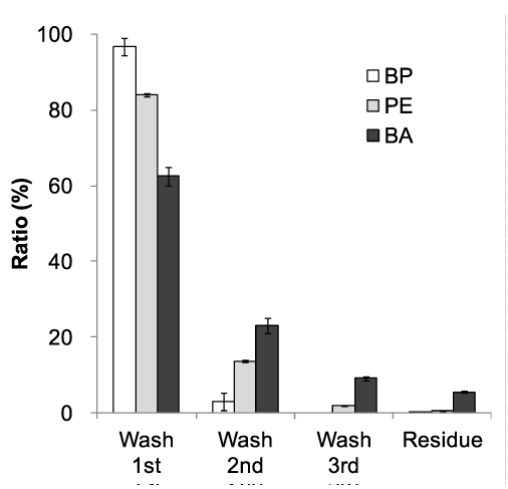

Figure 5: The removal of BP, PE, and BA after each washing cycle, and the ratio of residual to initial amount of the compounds in PVA towels (error bars indicate \pm standard deviation).

\begin{tabular}{|c|c|c|c|c|c|c|}
\hline & \multicolumn{3}{|c|}{ Isothiazolinones } & \multicolumn{3}{|c|}{ Others } \\
\hline & \multicolumn{3}{|c|}{$(\mu \mathrm{g} / \mathrm{g}$-wet) } & \multicolumn{3}{|c|}{$(\mu \mathrm{g} / \mathrm{g}$-wet $)$} \\
\hline \multicolumn{7}{|l|}{ Sample No. } \\
\hline & $\mathrm{Ml}$ & CMI & OIT & BP & PE & BA \\
\hline No.1 & 49 & 173 & n.d. & 2303 & n.d. & n.d. \\
\hline No.2 & 35 & 106 & n.d. & 895 & 99 & n.d. \\
\hline No.3 & n.d. ${ }^{a}$ & n.d. & n.d. & n.d. & n.d. & 23043 \\
\hline No.4 & 43 & 129 & n.d. & 442 & n.d. & n.d. \\
\hline No.5 & n.d. & n.d. & n.d. & 538 & n.d. & n.d. \\
\hline No.6 & 54 & 124 & n.d. & n.d. & n.d. & n.d. \\
\hline No.7 & 7.9 & 9.5 & n.d. & n.d. & n.d. & n.d. \\
\hline No.8 & 7.9 & 33 & n.d. & 194 & 3171 & n.d. \\
\hline No.9 & $2.9^{\mathrm{b}}$ & $9.3^{b}$ & n.d. & $160^{\mathrm{b}}$ & n.d. & n.d. \\
\hline No.10 & n.d. & n.d. & 484 & 124 & n.d. & n.d. \\
\hline No.11 & 14 & 53 & n.d. & 586 & n.d. & n.d. \\
\hline No.12 & n.d. & n.d. & n.d. & n.d. & n.d. & 1896 \\
\hline No.13 & 10 & 24 & n.d. & 121 & 1397 & n.d. \\
\hline No.14 & 84 & 168 & n.d. & n.d. & n.d. & n.d. \\
\hline No.15 & 29 & 101 & n.d. & 134 & n.d. & n.d. \\
\hline No.16 & 23 & 69 & n.d. & 510 & n.d. & n.d. \\
\hline No.17 & 28 & 110 & n.d. & 68 & n.d. & n.d. \\
\hline No.18 & 69 & 161 & n.d. & n.d. & n.d. & n.d. \\
\hline No.19 & 21 & 63 & n.d. & 232 & n.d. & n.d. \\
\hline No.20 & 19 & 60 & n.d. & 516 & n.d. & n.d. \\
\hline No.21 & n.d. & n.d. & n.d. & 887 & n.d. & n.d. \\
\hline $\begin{array}{l}\text { Frequency } \\
(\%)\end{array}$ & 76 & 76 & 4.8 & 71 & 14 & 9.5 \\
\hline
\end{tabular}

Table 3: ${ }^{a}$ Not detected; b Dry weight basis; Concentrations and detection frequencies of preservatives in PVA towels studied.

\section{Possibility of allergic contact dermatitis by PVA cooling towels}

The concentrations of isothiazolinone preservatives detected in this study were similar to those detected in the previous study [4]. Although isothiazolinone preservatives were detected in 17 samples, the product notes of 10 samples did not describe the use of isothiazolinone preservatives. Since PVA cooling towels could come into direct and sustained contact with human skin, the PVA cooling towels should be used with caution, especially on patients who are sensitive to isothiazolinone preservatives.

Occupational contact dermatitis due to $\mathrm{BP}$ [8] and a positive reaction in the patch test of $\mathrm{BP}$ was reported $[9,10]$. Skin irritation and 
Citation: Kawakami T, Isama K, Ikarashi Y (2015) Analysis of 19 preservatives in Polyvinyl Alcohol Cooling Towels Used in Japan by High Performance Liquid Chromatography with Photo Diode Array Detector. J Environ Anal Chem 2: 122. doi:10.4172/JREAC.1000122

Page 6 of 6

skin sensitization response in the patch test are induced at a concentration of $0.5 \%$ and $0.25 \%$ of $\mathrm{BP}$, respectively [8-10]. The European Union (EU) has regulated the concentration of BP in cosmetic products to less than $0.1 \%$ [11]. The maximum concentration of $\mathrm{BP}$ detected in this study was lower than the concentration required causing a skin sensitization. Furthermore, BP in the PVA towels was removed by the washing procedure.

Additionally, a negative reaction by patch testing of $\mathrm{PE}(1 \%)$ was reported [12]. In Japan, the concentrations of PE and BA used in cosmetic products and quasi-drugs must be less than $1.0 \%$ and $0.2 \%$, respectively $[13,14]$. The maximum concentration of PE detected in this study was lower than the regulated value. In contrast, the concentration of BA detected in No. 3 was higher than the permitted value. However, the concentration of BA detected in washed towels was lower than the regulated value. Accordingly, skin sensitizing is likely not occurred by the presence of BP, PE, and BA in PVA towels.

Notably, most product notes describing the use of preservatives in the PVA cooling towels were insufficient, owing to impertinent descriptions. Thus, manufactures should provide sufficient information about the preservatives used in the PVA towel products to prevent adverse health effects such as contact dermatitis.

\section{Conclusion}

In the summer of 2013, the clinical information regarding contact dermatitis due to using PVA cooling towels containing other preservatives was provided from the supplier of PVA towel. Thus, we analyzed 19 preservatives in 21 PVA towels using HPLC/PDA. A good separation of these preservatives was observed using InertSustain ${ }^{\circ}$

Phenyl column and $0.1 \%$ formic acid solution as the mobile phase. MI and CMI were detected in 16 samples. OIT was detected in one sample. BP, PE, PA were detected in 15, 3, and 2 samples, respectively. Other preservatives were not detected. Although isothiazolinone preservatives were detected in 17 samples, the product notes of 10 products, including the product with clinical information, did not describe about the use of isothiazolinone preservatives. Since PVA cooling towels in contact with human skin for a long time, the PVA cooling towels should be used with caution, especially on patients who are already sensitive to isothiazolinone preservatives. Furthermore, we evaluated the effectiveness of the washing process on the removal of
$\mathrm{BP}, \mathrm{PE}$, and BA from the PVA towels before their initial use. The results of this laboratory-simulated washing procedure suggest that contact dermatitis is likely not related to the presence of $\mathrm{BP}, \mathrm{PE}$, and BA in washed PVA towels.

\section{References}

1. Fukunaga A, Nishiyama S, Shimizu H, Nagai H, Horikawa T (2010) Nonoccupational allergic contact dermatitis from 2-n-octyl-4isothiazolinon-3-one in a Japanese mattress gel-sheet used for cooling. Cont Dermat 62: 317-318.

2. National Consumer Affair Center of Japan. Product test - The towel used for cooling.

3. Kawakami T, Isama K, Nishimura T (2012) Analysis of isothiazolinones and other preservatives in gel-products used for cooling in Japan. J Environ Chem 22: 205-211.

4. Kawakami T, Isama K, Ikarashi Y (2014) Analysis of isothiazolinone preservatives in polyvinyl alcohol cooling towels used in Japan. J Environ Sci health, Part A 49: 1209-1217.

5. Japanese Industrial Standard Committee. JIS K 0124:2011 General rules for high performance liquid chromatography.

6. Nakamura M (2008) Quality assurance and quality control of instrumental analysis: Analysis methods for pesticides and other organic compounds by GC/MS and LC/MS. Soft Science, Tokyo.

7. Nagasechemtex. http://www.nagasechemtex.co.jp/products/NS-BP.pdf.

8. Podmore P (2000) Occupational allergic contact dermatitis from both 2bromo-2-nitoropropane-1,3-diol and methylchloroisothiazolinone plus methylisothiazolinone in spin finish. Cont Dermat 43: 45.

9. Peters MS, Connolly SM, Schroeter AL (1983) Bronopol allergic contact dermatitis, Cont Dermat 9: 397-401.

10. Frosch PJ, White IR, Rycroft RJG, Lahti A, Burrows D (1990) Contact allergy to bronopol. Cont Dermat 22: 24-26.

11. European Union (2009) Regulation (EC) No 1223/2009 of the European parliament and of the council of 30 November 2009 on cosmetic products. OJEU L 342: 59-209.

12. Erdmann SM, Sachs B, Merk HF (2001) Allergic contact dermatitis due to methyldibromo glutaronitorile in Euxyl $\mathrm{K} 400$ in an ultrasonic gel. Cont Dermat 44: 39-40.

13. Ministry of Health, Labour and Welfare, Japan (29 september, 2000) Notification No 311.

14. Ministry of Health, Labour and Welfare, Japan. Yakusyokushinsahatsu No.0327004 (in Japanese). 